Article

\title{
Improvement of Comfort in Suspension Seats with a Pneumatic Negative Stiffness System
}

\author{
Eduardo Palomares *(D), Angel L. Morales (D), Antonio J. Nieto (D), Jose M. Chicharro $\mathbb{D}$ \\ and Publio Pintado
}

E.T.S. Ingeniería Industrial de Ciudad Real, University of Castilla-La Mancha, 13071 Ciudad Real, Spain;

AngelLuis.Morales@uclm.es (A.L.M.); AntonioJavier.Nieto@uclm.es (A.J.N.);

JoseManuel.Chicharro@uclm.es (J.M.C.); Publio.Pintado@uclm.es (P.P.)

* Correspondence: Eduardo.Palomares@uclm.es

Received: 8 November 2020; Accepted: 1 December 2020; Published: 3 December 2020

\begin{abstract}
This paper presents a Negative Stiffness System (NSS) for vibration isolation and comfort improvement of vehicle seats, which enhances the performance of optimized traditional passive seat suspensions. The NSS is based on a set of two Pneumatic Linear Actuators (PLAs) added to a seat supported by a pneumatic spring. One end of each PLA is joined to the seat while the other end is joined to the vehicle frame. In static conditions, the PLAs remain horizontal, whereas in dynamic conditions, their vertical forces work against the pneumatic spring, reducing the overall dynamic stiffness and improving passenger comfort. The paper presents a stability analysis of the highly nonlinear dynamic system, as well as the numerical determination of the optimum PLA pressure for a given passenger mass that maximises comfort without instabilities. Finally, the performance of the proposed NSS is compared to that of a traditionally optimized passive seat suspension via simulations of an eight-degree-of-freedom vehicle model traversing several road profiles and speed bumps. Comfort improvements between $10 \%$ and $35 \%$ are found in all tests considered.
\end{abstract}

Keywords: vibration isolation; negative stiffness system; comfort; suspension seat

\section{Introduction}

Long exposure times to vibrations may cause not only discomfort and fatigue, but also musculoskeletal stress or even permanent injuries. Thus, the minimisation of vibrations applied to the human body is important in applications in which operators must remain seated or standing subjected to periodic, random and transient vibration sources for long periods of time. This is common in occupations related to the transport sector, such as drivers of transport vehicles and heavy machinery, train attendants and airline crew members.

The response of the human body exposed to vibration has been studied by many researchers, the studies carried out by Griffin [1-4] being especially relevant. The relevance of the topic has led to the standardisation of methods for the quantification of whole-body vibration, which is continuously revised. The ISO 2631-1 standard [5] considers vibrations that affect human health, comfort, perception and motion sickness. More specific standards can also be found, such as the EN 12299 standard [6], which applies specifically to ride comfort for passengers in railway applications.

Leaving aside the optimisation of the cushion of the vehicle seat, a first approach to this topic has been the optimisation of passive secondary suspensions to connect the seat to the vehicle frame. Maciejewski et al. [7,8] optimized a seat with a viscous-elastic passive suspension, whose vibro-isolation properties are improved by a modification of an air-spring and shock absorber. Wan and Schimmels $[9,10]$ optimized linear and non-linear secondary suspensions. The latter ensures good vibration isolation with a small stiffness for small displacements and a larger stiffness for large 
displacements. Bouazara et al. [11] optimized the seat in a vehicle model with nine degrees of freedom. Abbas et al. [12] also optimized a seat suspension (as well as the vehicle suspension) by using a genetic algorithm. These works agree on optimal stiffness values in the range $5-8 \mathrm{kN} / \mathrm{m}$, which, assuming a single degree of freedom and a mass of around $100 \mathrm{~kg}$, leads to filtering frequencies $\left(\sqrt{2} f_{n}\right)$ lower than $2 \mathrm{~Hz}$, which is the lower bound of the more harmful frequency band according to ISO 2631-1. Nevertheless, these low stiffnesses involve several drawbacks such as a high static deflection highly sensitive to mass variations or a high likelihood of impacts against bump stops. Some of these drawbacks can be solved by using an optimized pneumatic secondary suspension as described by Hostens et al. [13].

Other authors have opted for active seat suspensions. Shimogo et al. [14] constructed an active seat suspension using a DC servo-motor, which is controlled by an optimal control algorithm. Stein [15] proposed an actively controlled electro-pneumatic actuator. Choi et al. [16] presented a semiactive control of an electrorheological seat suspension and evaluated ride comfort by means of hardware-in-the-loop simulations. Guclu [17] developed a fuzzy logic seat vibration control considering an eight-degree-of-freedom vehicle model. Bouazara et al. [11] compared optimized passive suspensions with active and semiactive seat suspension controls in a 3D vehicle model. Du et al. [18] designed a Magnetorheological (MR) elastomer isolator for a semiactive variable stiffness vibration control. Phu et al. [19] presented a hybrid controller for an MR damper based on a combination of three control schemes: fuzzy neural control, PI control and sliding mode control. Maciejewski et al. [20] used pneumatic muscles to actively control seats subjected to horizontal vibrations. In spite of the improvements claimed, active control always involves higher costs and more implementation difficulties than passive systems.

An alternative approach is to use Negative Stiffness Systems (NSSs) or isolators with zero dynamic stiffness. These systems or mechanisms show a much lower dynamic stiffness in comparison to the static one, and this paves the way for achieving the lowest filtering frequency possible without compromising other features. Lee et al. used springs with negative stiffness to improve occupant vibration isolation in the low frequency range in the seats of road vehicles and high-speed railway vehicles [21,22]. Le and Ahn [23,24] used a negative stiffness structure consisting of a couple of confronted springs perpendicular to the mass displacement, which generate a net vertical restoring force when there is a relative displacement between the cabin floor and the seat. Later, they also included an actively controlled pneumatic actuator to enhance the filtering capabilities of their negative stiffness system [25]. Other recent solutions are based on Euler beams [26], magnetic springs [27] and pneumatic actuators [28].

In this work, a seat suspension with a passive pneumatic spring is performed along with an NSS focusing on the stability of the global nonlinear system. The proposed seat suspension makes the most of pneumatic devices and passive negative stiffness mechanisms. The elements of the suspension are optimized in order to maximise driver comfort in accordance with the ISO 2631-1 standard, and the simulations are carried out in a vehicle model of eight degrees of freedom. The behaviour of the proposed suspension is compared to a passive seat suspension (optimal, so that the comparison is fair) under habitual perturbations such as different road profiles and speed bumps.

\section{Vehicle and Seat Suspension Model}

\subsection{Seat Suspension Model}

Figure 1 shows the configuration of the seat suspension composed of a pneumatic spring and a pneumatic negative stiffness mechanism. The seat is isolated from the vehicle frame via an air-spring (labelled 1) connected to an air compressor (labelled 2). Pressure is regulated with a precision pressure-control valve (labelled 3) and an on-off solenoid valve (labelled 4). The static pressure depends on the mass since a specific static suspension travel, measured by an LVDT (labelled 5), is required for the correct performance of the negative stiffness mechanism. The negative stiffness 
system consists of a pair of pneumatic linear actuators (labelled 6) placed symmetrically at each side of the air-spring. The actuators are placed facing each other, and in static conditions, LVDT measurements and the pressurised pneumatic spring make sure they remain perpendicular to the seat relative displacement $\left(z_{p}(t)-z_{b}(t)\right)$ direction. The end of each actuator rod is connected via a ball joint to the seat frame, while the end of the actuator body is connected in the same manner to the vehicle frame. The twin pneumatic actuators must remain pressurised up to a constant value (which depends on the sprung mass) that optimises the performance of the isolator system. Thus, a precision pressure-control valve (labelled 7) and an on-off solenoid valve (labelled 8) are included to regulate pressure.

The schematic of the vibration isolator equipped with a pneumatic negative stiffness system is shown in Figure 2, and its equation of motion is:

$$
m_{p} \ddot{z}_{p}=F_{S}-m_{p} g+F_{\mathrm{NSS}}=-\widehat{F}_{s}+F_{\mathrm{NSS}}
$$

where $m_{p}$ is the sprung mass, $z_{p}$ its vertical displacement, $z_{b}$ the vertical displacement of the cabin floor, $g$ the gravitational acceleration, $F_{S}$ the spring force, $\widehat{F}_{S}$ the static force minus the spring force and $F_{\text {NSS }}$ the vertical force supplied by the negative stiffness system.

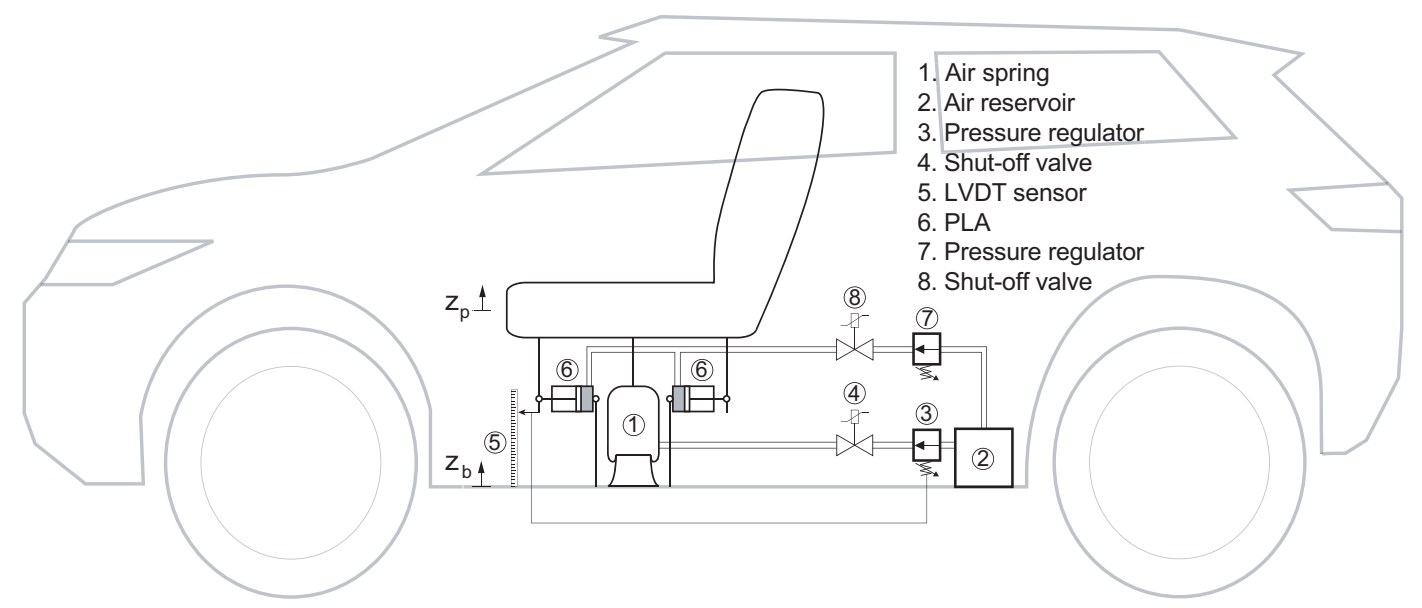

Figure 1. Schematics of the NSS on a vehicle.

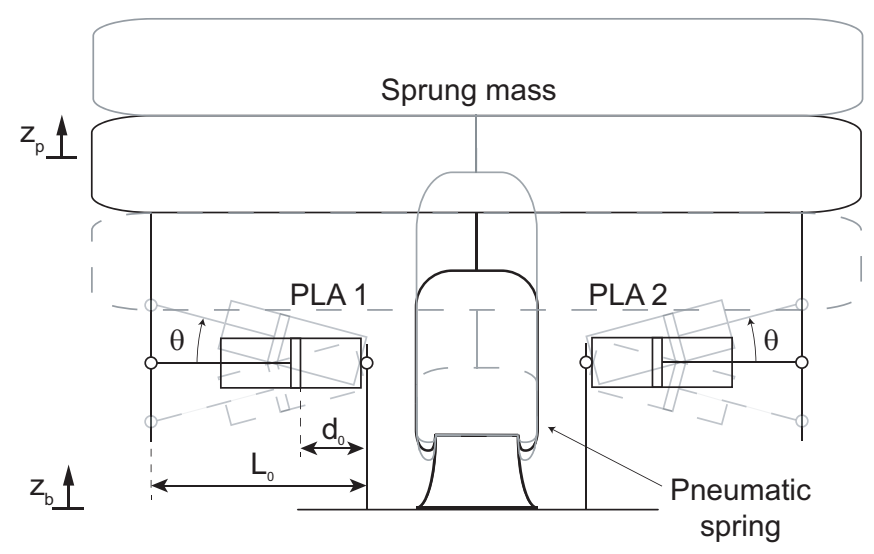

Figure 2. NSS working principle.

The pneumatic spring force can be modelled as the sum of two terms, one related to pressure, volume and area variations due to its relative displacement $\left(z_{s}=z_{p}-z_{b}\right)$, represented as a polytropic process, and a second related to structural damping:

$$
F_{\mathrm{s}}=\left[P_{s 0}\left(\frac{V_{s 0}}{V_{s}}\right)^{n_{s}}-P_{a}\right] A_{s}-\frac{\epsilon_{s}}{2 \pi f} \dot{z}_{s}
$$


where $P_{s 0}$ is the initial pressure of the air spring, $P_{a}$ the ambient pressure, $A_{s}$ and $V_{s}$ the effective area and volume, respectively, of the pneumatic spring (as functions of the relative displacement $z_{s}$ and initial pressure $\left.P_{s 0}\right), V_{s 0}$ its initial volume, $n_{s}$ the polytropic index, $\epsilon_{s}$ the structural damping constant of the air spring and $f$ the excitation frequency.

The net NSS force (in the vertical direction since the horizontal components cancel each other) depends on the seat suspension travel and the distance between the actuator ball joints $L_{0}$ when in the horizontal (static) position:

$$
F_{\mathrm{NSS}}=2 F_{\mathrm{PLA}} \frac{z_{s}}{\sqrt{L_{0}^{2}+z_{s}^{2}}}
$$

$F_{\text {PLA }}$ being the force exerted by each actuator with pressurised rear chambers, the model of which (previously detailed and validated by [29]) is:

$$
F_{\mathrm{PLA}}=A\left[P_{0}\left(\frac{d_{0}}{d_{0}+d}\right)^{n}-P_{a}\right]-\frac{\epsilon_{1}}{2 \pi f} \dot{d}-\operatorname{sgn}(\dot{d}) \epsilon_{2}\left(P_{0}-P_{a}\right)
$$

where $A$ is the effective area of the actuator piston, $P_{0}$ the initial pressure in the rear chambers, $n$ the polytropic index of this process, $d_{0}$ its initial displacement with respect to the fully contracted position (Figure 2), $d$ the piston additional displacement, $\epsilon_{1}$ the structural damping parameter of the actuator, $\epsilon_{2}$ its Coulomb friction parameter and $f$ the excitation frequency. Note that the piston additional displacement $d$ depends on the relative displacement $z_{s}$ as:

$$
d=\sqrt{L_{0}^{2}+z_{s}^{2}}-L_{0}
$$

\subsection{Vehicle Model}

The model of the pneumatic isolator is added to a seven-degree-of-freedom system representing a full vehicle (Figure 3). The seven degrees of freedom are: vehicle centre of mass bounce $(z)$, vehicle pitch $(\theta)$ and roll $(\varphi)$ and the four vertical displacements of the unsprung masses at each corner $\left(z_{t, f l}, z_{t, f r}\right.$, $z_{t, r l}$, and $\left.z_{t, r r}\right)$, where the first sub-index after the comma defines front $(f)$ or rear $(r)$ and the second left $(l)$ or right $(r)$. The relative position of the NSS on the cabin floor with respect to the centre of mass of the vehicle is defined with the vector $\mathbf{r}_{\mathbf{b}}$, the components of which are $r_{b x}, r_{b y}$, and $r_{b z}$.

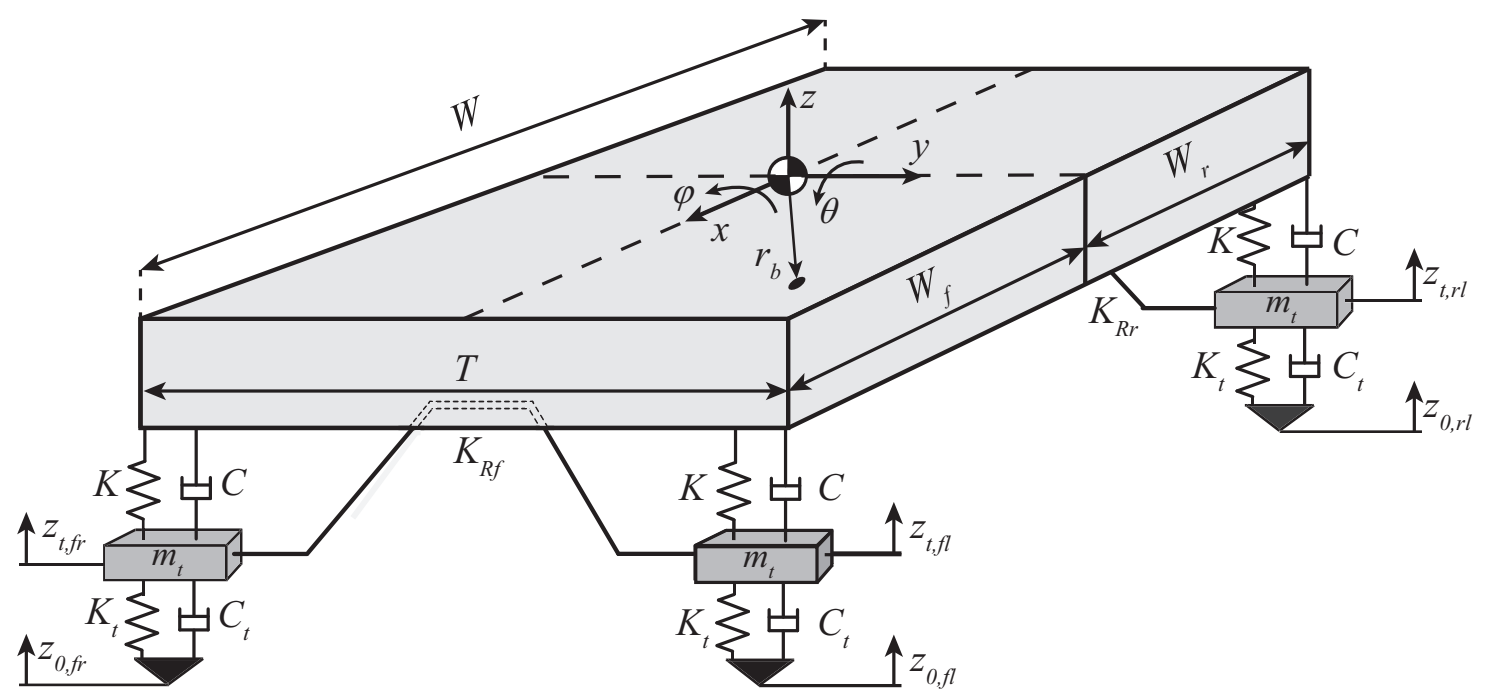

Figure 3. Seven-degree-of-freedom model.

The inputs to the model are the road profiles at each tyre $\left(z_{0, f l}, z_{0, f r}, z_{0, r l}\right.$, and $\left.z_{0, r r}\right)$. Other model parameters are the sprung mass $(m)$, the pitch and roll moments of inertia ( $I_{\theta}$ and $I_{\varphi}$, respectively), the four unsprung masses $\left(m_{t}\right)$, the wheelbase $\left(W\right.$, which is the sum of distances $W_{f}$ and $W_{r}$ in Figure 3$)$, 
the track width $(T)$, the suspension stiffness and damping ( $K$ and $C$ ) and the tyre stiffness and damping $\left(K_{t}\right.$ and $\left.C_{t}\right)$. The model also considers front and rear sway bars, the torques of which depend on their torsional stiffness $\left(K_{R f}\right.$ or $\left.K_{R r}\right)$ and their torsional angles due to the difference between the vehicle roll angle $(\varphi)$ and axle roll angle $\left(\varphi_{f}\right.$ or $\left.\varphi_{r}\right)$. The axle roll angle, for small amplitude oscillations, can be approximated by:

$$
\begin{aligned}
\varphi_{f} & \simeq \frac{z_{t, f l}-z_{t, f r}}{T} \\
\varphi_{r} & \simeq \frac{z_{t, r l}-z_{t, r r}}{T}
\end{aligned}
$$

With these definitions, the equations of motion of the eight-degree-of-freedom system (seven for the vehicle and one additional for the seat) are written as:

$$
\left\{\begin{aligned}
m \ddot{z}= & -K z_{f l}-C \dot{z}_{f l}-K z_{f r}-C \dot{z}_{f r}-K z_{r l}-C \dot{z}_{r l}-K z_{r r}-C \dot{z}_{r r}-\left(-\widehat{F}_{s}+F_{\mathrm{NSS}}\right) \\
I_{\varphi} \ddot{\varphi}= & \left(K z_{f r}+C \dot{z}_{f r}+K z_{r r}+C \dot{z}_{r r}-K z_{f l}-C \dot{z}_{f l}-K z_{r l}-C \dot{z}_{r l}\right) \frac{T}{2} \\
& -K_{R, f}\left(\varphi-\varphi_{f}\right)-K_{R, r}\left(\varphi-\varphi_{r}\right)-\left(-\widehat{F}_{s}+F_{\mathrm{NSS}}\right) r_{b y} \\
I_{\theta} \ddot{\theta}= & \left(K z_{f l}+C \dot{z}_{f l}+K z_{f r}+C \dot{z}_{f r}\right) W_{f}-\left(K z_{r l}+C \dot{z}_{r l}+K z_{r r}+C \dot{z}_{r r}\right) W_{r} \\
& +\left(-\widehat{F}_{s}+F_{\mathrm{NSS}}\right) r_{b x} \\
m_{t} \ddot{z}_{t, f l}= & K z_{f l}+C \dot{z}_{f l}-K_{t}\left(z_{t, f l}-z_{0, f l}\right)-C_{t}\left(\dot{z}_{t, f l}-\dot{z}_{0, f l}\right)+K_{R, f}\left(\varphi-\varphi_{f}\right) / T \\
m_{t} \ddot{z}_{t, f r}= & K z_{f r}+C \dot{z}_{f r}-K_{t}\left(z_{t, f r}-z_{0, f r}\right)-C_{t}\left(\dot{z}_{t, f r}-\dot{z}_{0, f r}\right)-K_{R, f}\left(\varphi-\varphi_{f}\right) / T \\
m_{t} \ddot{z}_{t, r l}= & K z_{r l}+C \dot{z}_{r l}-K_{t}\left(z_{t, r l}-z_{0, r l}\right)-C_{t}\left(\dot{z}_{t, r l}-\dot{z}_{0, r l}\right)+K_{R, r}\left(\varphi-\varphi_{r}\right) / T \\
m_{t} \ddot{z}_{t, r r}= & K z_{r r}+C \dot{z}_{r r}-K_{t}\left(z_{t, r r}-z_{0, r r}\right)-C_{t}\left(\dot{z}_{t, r r}-\dot{z}_{0, r r}\right)-K_{R, r}\left(\varphi-\varphi_{r}\right) / T \\
m_{p} \ddot{z}_{p}= & -\widehat{F}_{S}+F_{\mathrm{NSS}}
\end{aligned}\right.
$$

where the suspension travel at each corner of the vehicle $\left(z_{f l}, z_{f r}, z_{r l}\right.$, and $\left.z_{r r}\right)$ can be obtained as:

$$
\begin{aligned}
z_{f l} & =z-W_{f} \theta+\frac{T}{2} \varphi-z_{t, f l} \\
z_{f r} & =z-W_{f} \theta-\frac{T}{2} \varphi-z_{t, f r} \\
z_{r l} & =z+W_{r} \theta+\frac{T}{2} \varphi-z_{t, r l} \\
z_{r r} & =z+W_{r} \theta-\frac{T}{2} \varphi-z_{t, r r}
\end{aligned}
$$

and $\widehat{F}_{S}$ and $F_{\mathrm{NSS}}$ depend on the relative displacement of the pneumatic spring $\left(z_{s}=z_{p}-z_{b}\right.$; see Equations (2) and (3), $z_{b}$ being the absolute displacement of the base of the NSS placed at the driver's seat.

$$
z_{b}=z-r_{b x} \theta+r_{b y} \varphi
$$

\section{Optimal NSS Stiffness}

For isolation purposes, the natural frequency of the suspension system should be as low as possible. Unlike traditional passive seat suspensions, the NSS allows an additional reduction of the resonance frequency in dynamic conditions. For better performance of the NSS, the pneumatic isolator is required to present an inherent low stiffness. With this in mind, a Firestone W02-358-7010 pneumatic spring that provides a natural frequency in the vicinity of $f_{n}=1.7 \mathrm{~Hz}$ was selected. This device has been modelled and validated in previous works [28], and its force is expressed as shown in Equation (2). In accordance with this expression, its stiffness is not constant, but a function of initial pressure $P_{s 0}$ and relative displacement $z_{s}$. An example to show the stiffness variation of this pneumatic spring, initially pressurised to support a passenger of $75 \mathrm{~kg}\left(P_{s 0}=3.77\right.$ bar abs.) can be seen in Figure 4 .

The search for commercial pneumatic linear actuators for the NSS must take into consideration stability requirements and a compact design. In this case, a double-effect single-rod actuator, Model RA/192050/MX/40, manufactured by Norgren complying with the ISO 15552 standard, was chosen. The piston is $50 \mathrm{~mm}$ in diameter $\left(A=1800 \mathrm{~mm}^{2}\right)$; the rod is $20 \mathrm{~mm}$ in diameter; the stroke is $40 \mathrm{~mm}$; and the static distance between ball joints of each PLA is $L_{0}=172 \mathrm{~mm}$, which, as mentioned (Figure 2), includes the initial displacement $d_{0}=10 \mathrm{~mm}$. 
Before the NSS is activated, a basic control system must regulate the initial pressure in the pneumatic spring $\left(P_{s 0}\right)$ so that the static deflection of the seat allows the pneumatic linear actuators to face each other in a horizontal position, perpendicular to the sprung mass displacement. This fact can be obtained by simply tuning a PID controller to keep the static deflection (measured by an LVDT) in the required set point.

The equation of motion of the vibration isolator is:

$$
m_{p} \ddot{z}_{p}=-\widehat{F}_{S}+F_{\mathrm{NSS}}
$$

One may define the restoring force as the force that tries to bring back the sprung mass to its equilibrium position, that is:

$$
F_{r}=\widehat{F}_{s}-F_{\mathrm{NSS}}
$$

Thus, the NSS reduces the restoring force. The goal now is to determine the optimum $F_{\text {NSS }}$ to minimise the restoring force without making the system unstable; or, in terms of stiffness, to determine the optimum negative stiffness of the NSS without allowing a negative overall stiffness under any circumstances.

The overall stiffness $\left(k_{r}\right)$ can be obtained by differentiating the restoring force $\left(F_{r}\right)$ with respect to the relative displacement of the sprung mass $\left(z_{s}\right)$ :

$$
\begin{aligned}
k_{r}= & \left(P_{s 0}\left(\frac{V_{s 0}}{V_{s}\left(P_{s 0}, z_{s}\right)}\right)^{n_{s}}-P_{a}\right) \frac{\partial A_{s}\left(P_{s 0}, z_{s}\right)}{\partial z_{s}}-\frac{P_{s 0} n_{s} A_{s}\left(P_{s 0}, z_{s}\right)\left(\frac{V_{s 0}}{V_{s}\left(P_{s 0}, z_{s}\right)}\right)^{n_{s}} \frac{\partial V_{s}\left(P_{s 0}, z_{s}\right)}{\partial z_{s}}}{V_{s}\left(P_{s 0}, z_{s}\right)}- \\
& -2 A\left(P_{0}\left(\frac{d_{0}}{\alpha_{1}+\alpha_{2}}\right)^{n}-P_{a}\right) \frac{L_{0}^{2}}{\alpha_{2}^{3}}+2 A P_{0} n\left(\frac{d_{0}}{\alpha_{1}+\alpha_{2}}\right)^{n} \frac{z_{s}^{2}}{\left(\alpha_{1}+\alpha_{2}\right) \alpha_{2}^{2}}+ \\
& +\frac{2 z_{s} \dot{z}_{s}}{f \pi} \epsilon_{1} \frac{L_{0}^{2}}{\alpha_{2}^{4}}+2\left(P_{0}-P_{a}\right)\left(\operatorname{sign}\left(\frac{\dot{z}_{s} z_{s}}{\alpha_{2}}\right)+2 z_{s} \dot{z}_{s} \delta\left(\frac{\dot{z}_{s} z_{s}}{\alpha_{2}}\right)\right) \epsilon_{2} \frac{L_{0}^{2}}{\alpha_{2}^{3}}
\end{aligned}
$$

where $\alpha_{1}=\left(d_{0}-L_{0}\right), \alpha_{2}=\left(L_{0}^{2}+z_{s}^{2}\right)^{1 / 2}$ and $\delta$ is the Dirac delta function, which appears as the derivative of the sign function. This expression requires being computed numerically due to the nonlinearities and the experimental characterization of the effective area and volume of the pneumatic spring.

If structural and Coulomb damping of the PLA are neglected and the terms corresponding to the pneumatic spring dynamic stiffness are grouped into $k_{s}$, a more straightforward expression is obtained:

$$
k_{r}=k_{s}-2 A\left(P_{0}\left(\frac{d_{0}}{\alpha_{1}+\alpha_{2}}\right)^{n}-P_{a}\right) \frac{L_{0}^{2}}{\alpha_{2}^{3}}+2 A P_{0} n\left(\frac{d_{0}}{\alpha_{1}+\alpha_{2}}\right)^{n} \frac{z_{s}^{2}}{\left(\alpha_{1}+\alpha_{2}\right) \alpha_{2}^{2}}
$$

As mentioned, the goal of the NSS is to cancel the pneumatic spring dynamic stiffness. Nevertheless, there are infinite solutions, $\left(P_{0}, z_{s}\right)$ pairs that solve this problem. The only solution $\left(\bar{P}_{0}, \bar{z}_{s}\right.$ pair $)$ that keeps the system stable under any circumstances is that in which both stiffness curves are tangent, as can be seen in Figure 4a.

Figure 4a shows the stiffness of the pneumatic spring (when pressurised to support a passenger of $75 \mathrm{~kg}$ ), the optimum stiffness of the NSS and the resulting overall stiffness of the vibration isolator. In the optimum situation, the pneumatic spring stiffness and the NSS stiffness are tangent, which occurs for $\bar{P}_{0}=5.93$ bar abs. and $\bar{z}_{s}=5.39 \mathrm{~mm}$. This guarantees that the overall dynamic stiffness is not only zero, but also a minimum. Higher values of $P_{0}$ would raise the NSS stiffness and would also lead to zero dynamic stiffness (where both curves cross), but the overall stiffness could be negative and the system unstable. On the other hand, lower values of $P_{0}$ do not allow both curves to cross, and the minimum dynamic stiffness cannot be zero. Figure $4 \mathrm{~b}$ shows the system dynamic stiffness for different values of $P_{0}$ : when no pressure is applied, the system behaves as if it were simply supported on the pneumatic spring; for positive pressure below $\bar{P}_{0}$, the dynamic stiffness is smaller than the 
case before for any $z_{s}$; finally, if the limit pressure is exceeded, the dynamic stiffness reaches negative values; hence, the system becomes unstable, and the sprung mass will oscillate around a different equilibrium position.

As an example of the equilibrium of the system, free vibration after an initial displacement of $25 \mathrm{~mm}$ was simulated for these particular cases of initial pressure. Temporal responses and phase space trajectories are shown in Figure 5. For $P_{0}<\bar{P}_{0}$, the higher the pressure, the lower the displacement is (and also the velocities and accelerations); for $P_{0}>\bar{P}_{0}$, the system oscillates around a different equilibrium position at $z_{s}=40 \mathrm{~mm}$.

Thus, the required optimum parameters of the NSS can be obtained by solving the following system of nonlinear equations:

$$
\left\{\begin{array}{c}
\frac{\mathrm{d} F_{r}}{\mathrm{~d} z_{s}}=k_{r}=0 \\
\frac{\mathrm{d}^{2} F_{r}}{\mathrm{~d} z_{s}^{2}}=\frac{\mathrm{d} k_{r}}{\mathrm{~d} z_{s}}=0
\end{array}\right.
$$

which impose that the stiffness of the restoring force is zero and a minimum. This system of algebraic equations is highly nonlinear and dependent on the passenger mass, but can be numerically solved by methods such as Newton-Raphson. This method requires the use of an approximate solution as a seed to initiate the iterative process. A useful seed $\left(\bar{P}_{0}^{0}, \bar{z}_{s}^{0}\right.$ pair) can be obtained by considering $\bar{z}_{s}^{0}=0$ (as would occur if the pneumatic spring were linear) and neglecting structural and Coulomb damping. Plugging this value into Equation (13), the seed for the initial pressure has a simple analytical expression:

$$
\bar{P}_{0}^{0}=\frac{k_{s}\left(\bar{z}_{s}^{0}\right) L_{0}}{2 A}+P_{a}
$$

(a)

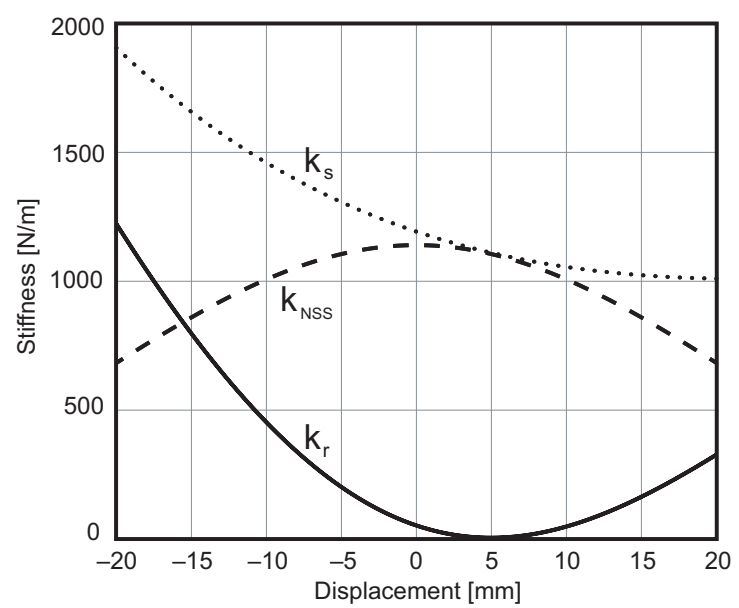

(b)

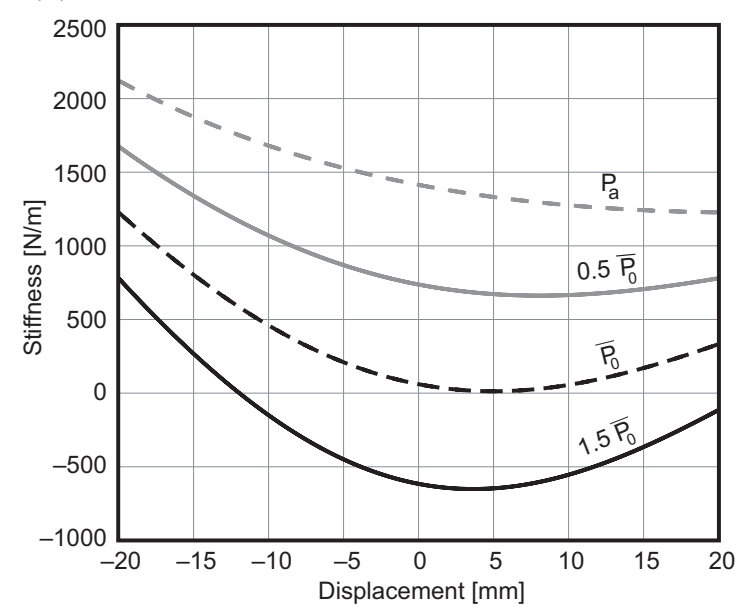

Figure 4. (a) Nonlinear stiffness of the pneumatic spring, NSS and vibration isolator with the optimum PLA pressure for a passenger mass of $75 \mathrm{~kg}$; and (b) nonlinear stiffness of the vibration isolator for different initial PLA pressures for a passenger mass of $75 \mathrm{~kg}$. 
(a)

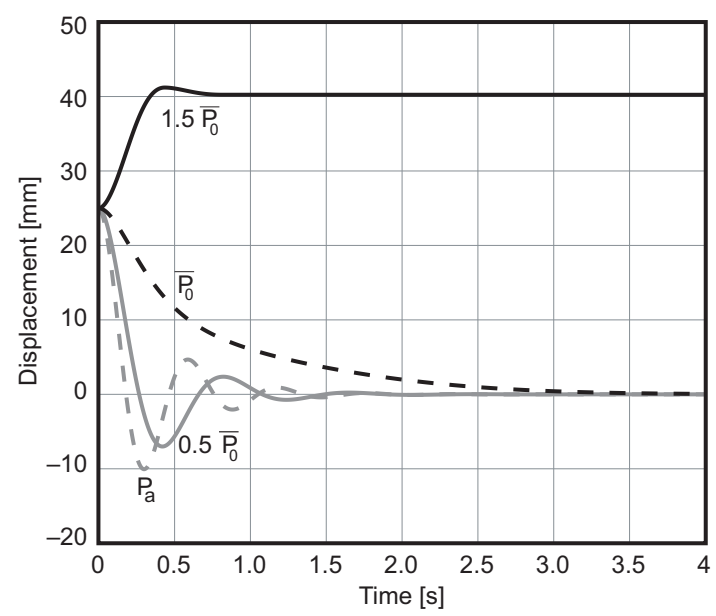

(b)

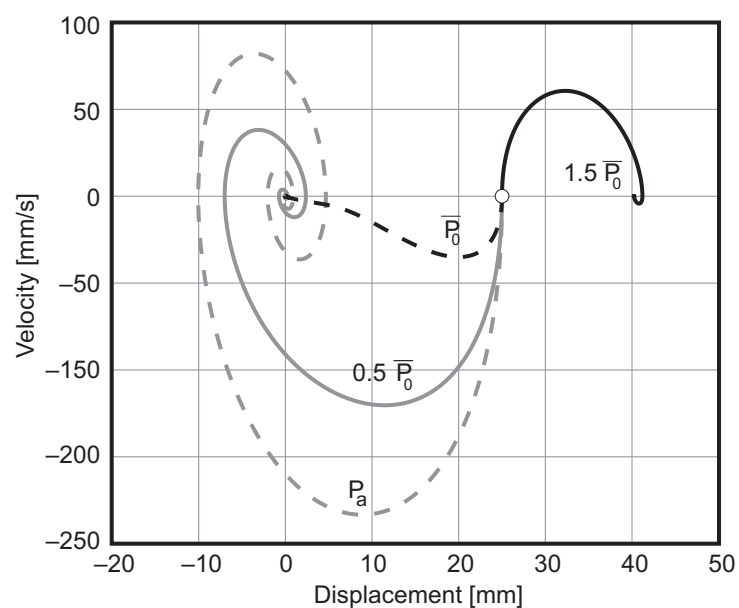

Figure 5. (a) Temporal responses and (b) phase space trajectories, corresponding to free vibration after an initial displacement of $25 \mathrm{~mm}$, for different initial PLA pressures and a passenger mass of $75 \mathrm{~kg}$.

\section{Numerical Simulations}

To appraise the performance of the vibration isolator, its response under different excitations will be compared to that of a traditional optimized passive system without NSS. Several works have dealt with the optimisation of a secondary suspension under the seat, obtaining values in the vicinity of $K=5 \mathrm{kN} / \mathrm{m}$ and $C=1 \mathrm{kNs} / \mathrm{m}$ [9-11]. To make a fair comparison between our proposed system and the passive seat suspension, these optimized values will be used. Realistic vehicle parameters are gathered in Table 1 , where $K$ and $C$ were chosen in the low range of the usual values for these parameters.

Table 1. Vehicle specifications.

\begin{tabular}{llrllrllr}
\hline$M$ & $(\mathrm{~kg})$ & 1472 & $K$ & $(\mathrm{~N} / \mathrm{m})$ & 35,000 & $K_{R f}$ & $(\mathrm{Nm} / \mathrm{rad})$ & 10,000 \\
$m_{t}$ & $(\mathrm{~kg})$ & 40 & $C$ & $(\mathrm{Ns} / \mathrm{m})$ & 2000 & $K_{R r}$ & $(\mathrm{Nm} / \mathrm{rad})$ & 12,000 \\
$I_{\varphi}$ & $\left(\mathrm{kg} \mathrm{m}^{2}\right)$ & 453 & $K_{t}$ & $(\mathrm{kN} / \mathrm{m})$ & 200 & $T$ & $(\mathrm{~m})$ & 1.5 \\
$I_{\theta}$ & $\left(\mathrm{kg} \mathrm{m}^{2}\right)$ & 2568 & $C_{t}$ & $(\mathrm{Ns} / \mathrm{m})$ & 180 & $W_{f}$ & $(\mathrm{~m})$ & 1.087 \\
& & & & & & $W_{r}$ & $(\mathrm{~m})$ & 1.472 \\
& & & & & & $W$ & $(\mathrm{~m})$ & 2.559 \\
\hline
\end{tabular}

\subsection{Road Profile}

In this first case study, the vehicle travels different road profiles. The excitation profiles are generated using the classical Sayers procedure [30], which assumes that the Power Spectral Density (PSD) of the vertical excitation can be represented by the expression:

$$
S_{z_{0}}(v)=S_{e}+\frac{S_{s}}{(2 \pi v)^{2}}+\frac{S_{a}}{(2 \pi v)^{4}}
$$

where $S_{e}, S_{s}$ and $S_{a}$ are constants and $v$ is the wavenumber. The procedure for generating random profiles involves generating white noises (elevation, slope and acceleration) of spectral densities $S_{e}, S_{s}$ and $S_{a}$, respectively. The desired sample profile will be the addition of the elevation noise, the integrated slope noise and the twice-integrated acceleration noise. Finally, excitations as a function of distance are converted into time records by dividing by the vehicle speed. Four different profiles corresponding to four ISO categories (A, B, C and D) will be considered in this case study, the realistic travelling speeds being $120 \mathrm{~km} / \mathrm{h}, 100 \mathrm{~km} / \mathrm{h}, 90 \mathrm{~km} / \mathrm{h}$ and $70 \mathrm{~km} / \mathrm{h}$. The PSDs of these time records can be seen in Figure 6. 
In addition to the different road profiles, the influence of the passenger mass is also analysed by considering three different masses: $60 \mathrm{~kg}$, $75 \mathrm{~kg}$ and $90 \mathrm{~kg}$.

Figures 7 and 8 show the PSD of the weighted acceleration of the driver for both, the system with and without NSS. Acceleration of the sprung mass was filtered following the indications of the ISO 2631-1 standard for the evaluation of human exposure to whole-body vibration in the vertical direction and seated position. Figure 7 shows the influence of the road profile for a constant passenger mass, whereas Figure 8 shows the influence of the mass when travelling the same road profile. A three second time lapse of the weighted acceleration versus time for a representative simulation (Type D profile and $60 \mathrm{~kg}$ ) is also shown in Figure 9. Qualitatively speaking, the behaviour of the isolator system with NSS is clearly better, in all circumstances, than the optimized system without NSS. This fact is also supported quantitatively by Table 2, where the root mean squared weighted acceleration of the driver $\left(\ddot{z}_{p, \text { rms }}\right)$ obtained for the two configurations, in all tests considered, are gathered. The use of the NSS proposed leads to comfort improvements between $10 \%$ (when the road profile is very smooth) and $23 \%$ when the road profile is poor. The influence of the mass is not very strong, but higher improvements are obtained for larger masses.

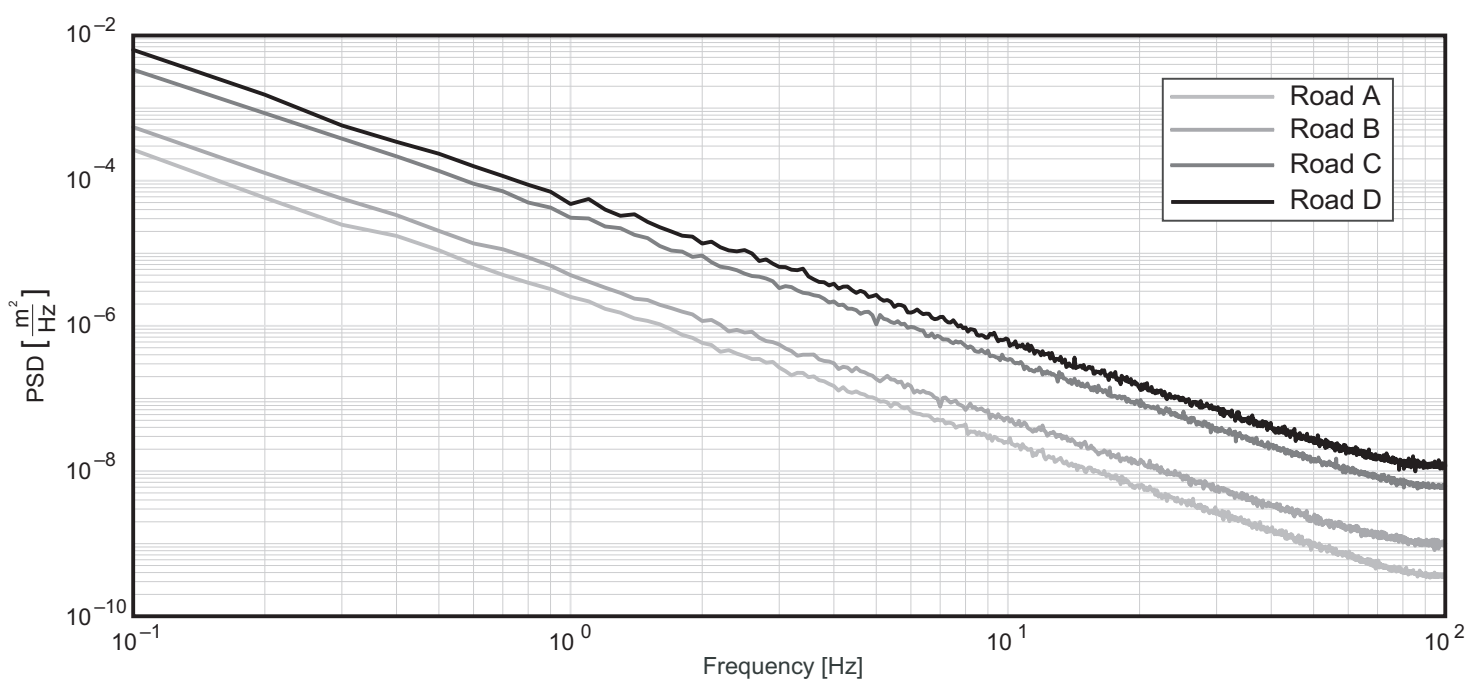

Figure 6. PSDs of the four road profiles.

(a)

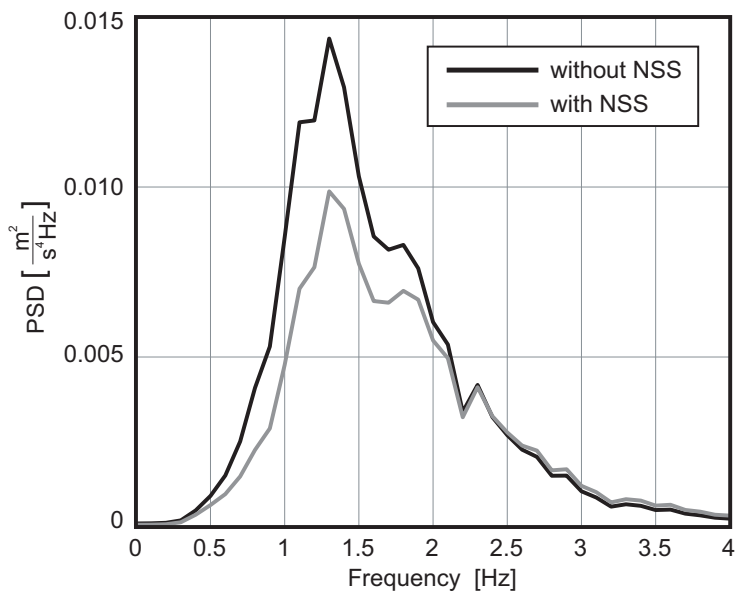

(b)

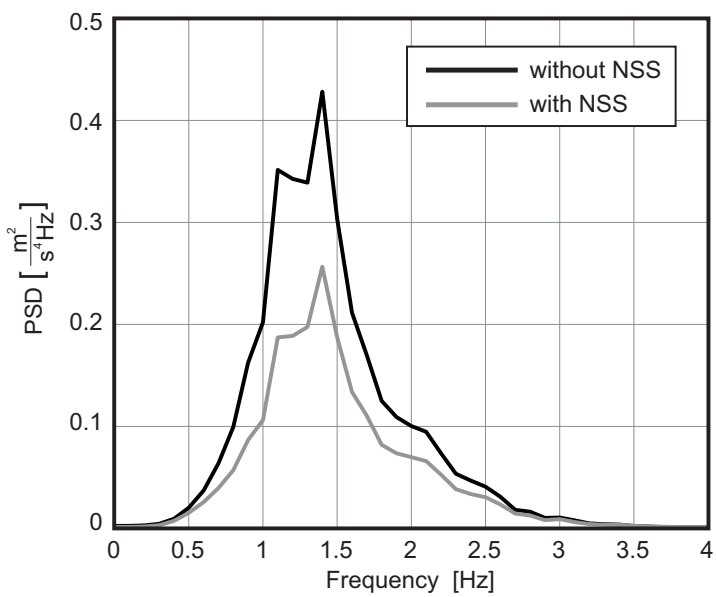

Figure 7. PSD of the weighted acceleration obtained with and without NSS for a driver of $75 \mathrm{~kg}$ and two different road profiles: (a) Type A and (b) Type D. 
(a)

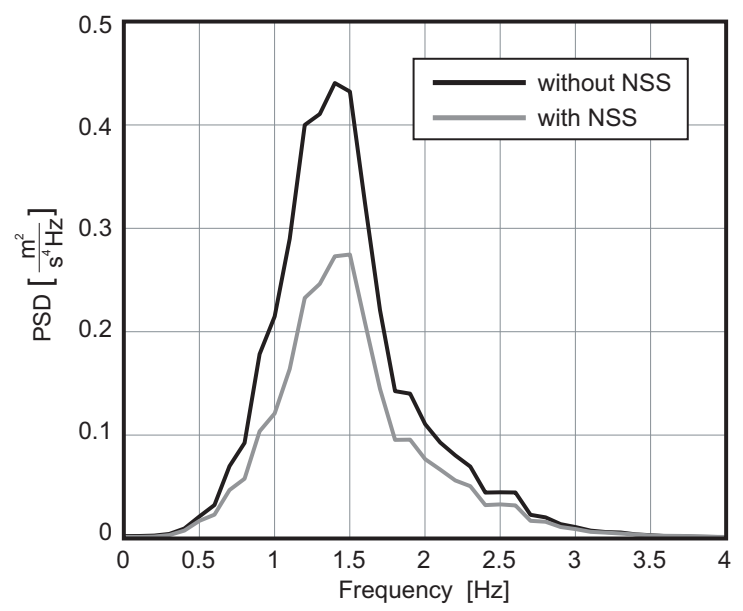

(b)

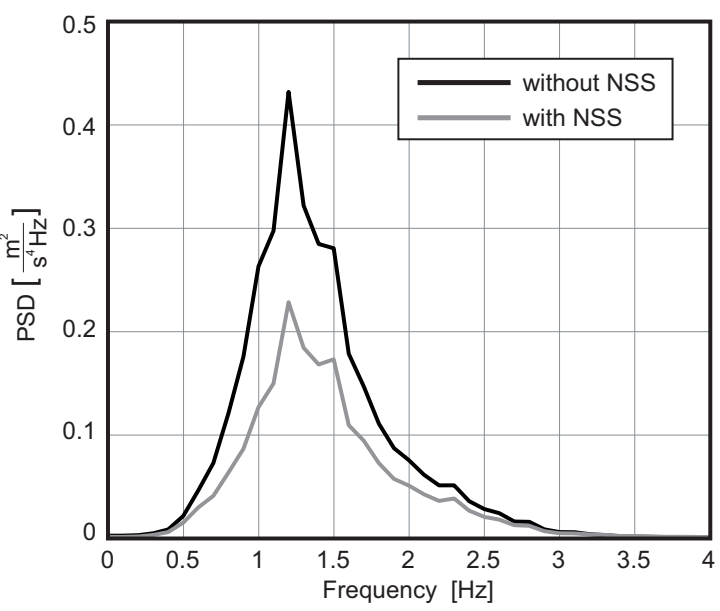

Figure 8. PSD of the weighted acceleration obtained with and without NSS for road profile Type D and two different masses: (a) $60 \mathrm{~kg}$ and (b) $90 \mathrm{~kg}$.

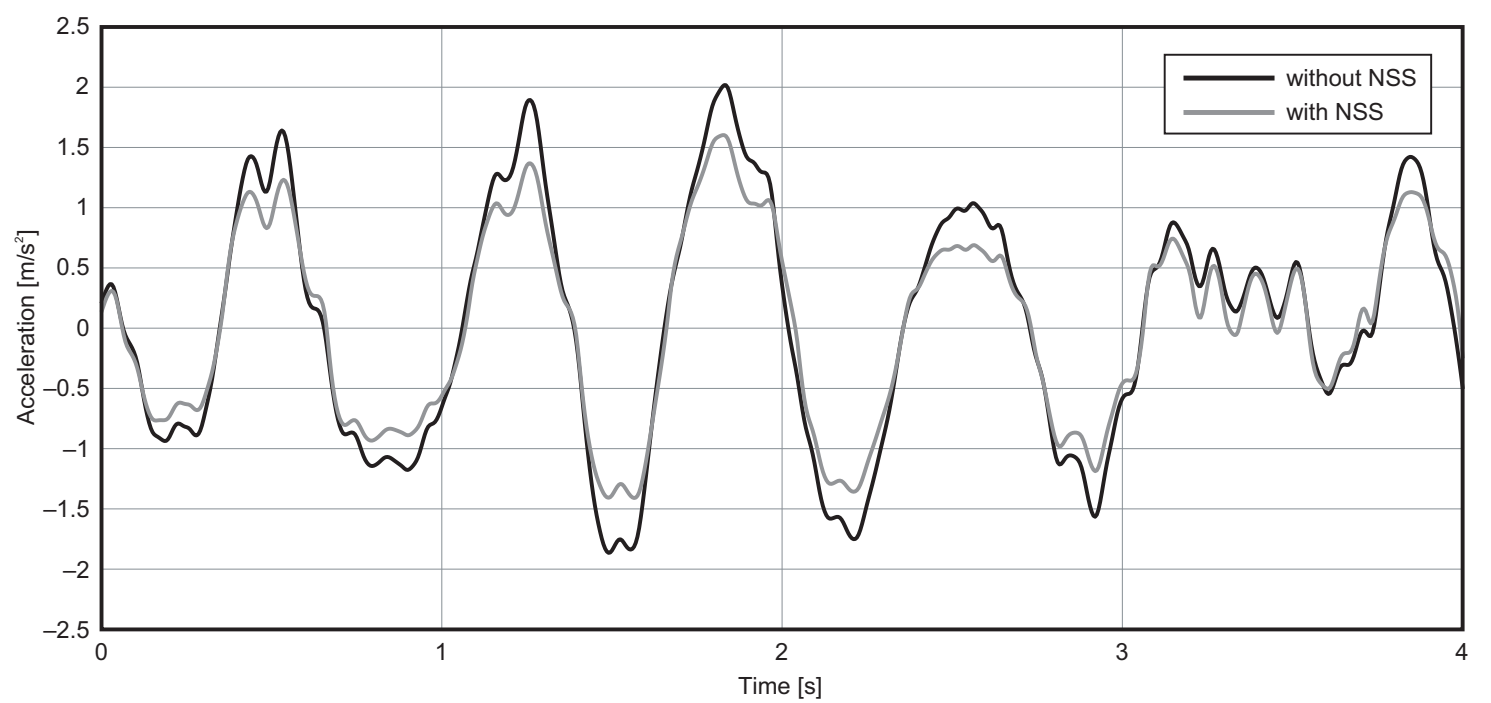

Figure 9. Close-up view of the weighted acceleration versus time for the Type D road profile and a mass of $60 \mathrm{~kg}$.

Table 2. Root mean squared weighted acceleration values for different road profiles and vehicle speeds.

\begin{tabular}{ccccc}
\hline Road Profile & $\begin{array}{c}\text { Mass } \\
(\mathbf{k g})\end{array}$ & $\begin{array}{c}\ddot{z}_{p, \text { rms }} \text { Passive } \\
\left(\mathbf{m} / \mathbf{s}^{2}\right)\end{array}$ & $\begin{array}{c}\ddot{z}_{p, \text { rms }} \text { NSS } \\
\left(\mathbf{m} / \mathbf{s}^{2}\right)\end{array}$ & $\begin{array}{c}\text { Variation } \\
\mathbf{( \% )}\end{array}$ \\
\hline \multirow{3}{*}{ Type A } & 60 & 0.129 & 0.116 & -10.08 \\
& 75 & 0.126 & 0.113 & -10.32 \\
& 90 & 0.116 & 0.103 & -11.21 \\
\hline \multirow{2}{*}{ Type B } & 60 & 0.180 & 0.159 & -11.67 \\
& 75 & 0.171 & 0.148 & -13.45 \\
& 90 & 0.163 & 0.139 & -14.72 \\
\hline \multirow{2}{*}{ Type C } & 60 & 0.431 & 0.355 & -17.63 \\
& 75 & 0.402 & 0.323 & -19.65 \\
& 90 & 0.378 & 0.296 & -21.69 \\
\hline \multirow{2}{*}{ Type D } & 60 & 0.648 & 0.522 & -19.44 \\
& 75 & 0.605 & 0.479 & -20.83 \\
& 90 & 0.581 & 0.450 & -22.55 \\
\hline
\end{tabular}




\subsection{Speed Bump}

The second case study is that of a vehicle traversing a speed bump, the shape of which is defined by the following expression [31]:

$$
z_{0}=H \sin ^{2} \frac{2 \pi v t}{L}
$$

where the height $(H)$ is $70 \mathrm{~mm}$ and the length $(L) 1500 \mathrm{~mm}$. The influences of the speed of the vehicle $(v)$ and the mass of the driver $\left(m_{p}\right)$ are analysed in the selected simulations.

Figures 10 and 11 show the acceleration of the driver when the vehicle travels with drivers of different masses at different speeds. Although the improvements are not outstanding, the maximum acceleration peak at the driver's position is significantly lower when the NSS is used. A quantitative comparison can be fount in Table 3 where the NSS is proven to provide comfort improvements (in this case, in terms of peak vertical acceleration) higher than $30 \%$ in all cases.

(a)

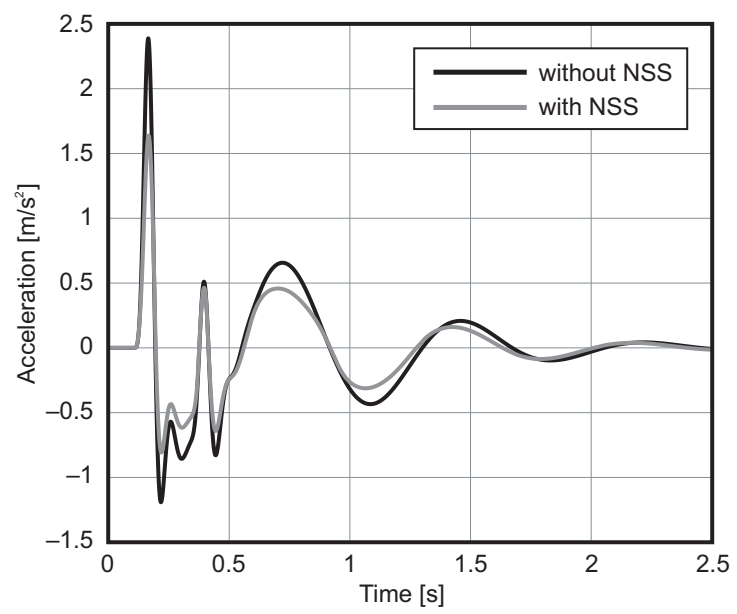

(b)

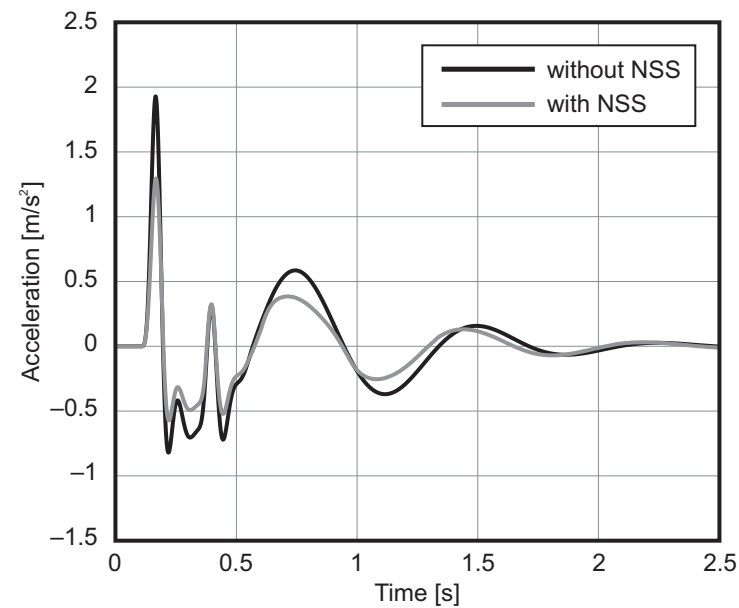

Figure 10. Acceleration values when traversing a speed bump at $40 \mathrm{~km} / \mathrm{h}$ with a mass of (a) $60 \mathrm{~kg}$ and (b) $90 \mathrm{~kg}$.

(a)

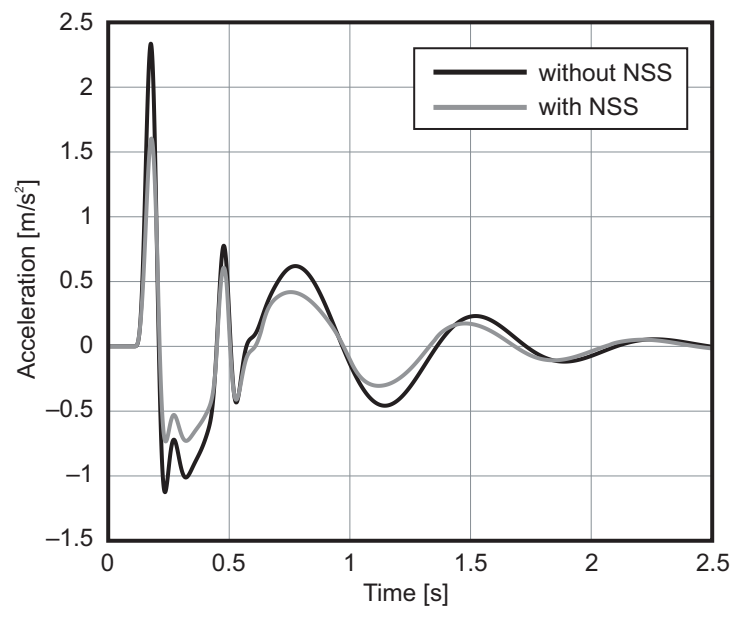

(b)

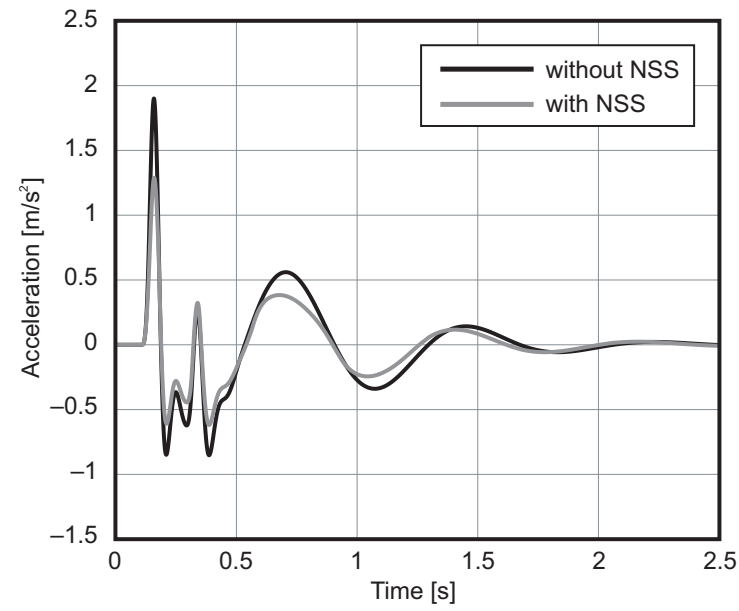

Figure 11. Acceleration values when traversing a speed bump with a mass of $75 \mathrm{~kg}$ at (a) $30 \mathrm{~km} / \mathrm{h}$ and (b) $50 \mathrm{~km} / \mathrm{h}$. 
Table 3. Peak acceleration values for a speed bump traversed with different speeds and masses.

\begin{tabular}{|c|c|c|c|c|}
\hline $\begin{array}{l}\text { Vehicle Speed } \\
\qquad(\mathrm{km} / \mathrm{h})\end{array}$ & $\begin{array}{l}\text { Mass } \\
(\mathrm{kg})\end{array}$ & $\begin{array}{c}\ddot{z}_{p, \max } \text { Passive } \\
\left(\mathrm{m} / \mathrm{s}^{2}\right)\end{array}$ & $\begin{array}{c}\ddot{z}_{p, \max } \text { NSS } \\
\left(\mathrm{m} / \mathrm{s}^{2}\right)\end{array}$ & $\begin{array}{c}\text { Variation } \\
(\%)\end{array}$ \\
\hline \multirow{3}{*}{30} & 60 & 2.915 & 2.022 & -30.63 \\
\hline & 75 & 2.614 & 1.794 & -31.37 \\
\hline & 90 & 2.368 & 1.609 & -32.05 \\
\hline \multirow{3}{*}{40} & 60 & 2.713 & 1.848 & -31.88 \\
\hline & 75 & 2.419 & 1.633 & -32.49 \\
\hline & 90 & 2.185 & 1.459 & -33.23 \\
\hline \multirow{3}{*}{50} & 60 & 2.459 & 1.667 & -32.21 \\
\hline & 75 & 2.187 & 1.469 & -32.83 \\
\hline & 90 & 1.971 & 1.311 & -33.49 \\
\hline
\end{tabular}

\section{Conclusions}

The vibration isolator presented in this paper, with the aim of improving comfort in vehicle seats, includes a passive and effective negative stiffness system based on standard, inexpensive and robust pneumatic devices. The proposed system proved its validity to provide a sufficient static stiffness and a reduced dynamic stiffness in order to maximise comfort. An NSS stability analysis of the highly nonlinear system led to an optimum PLA pressure, which guarantees that the minimum overall dynamic stiffness is equal to zero. Finally, the NSS performance was compared to that of an optimized passive seat suspension via simulations in an eight-degree-of-freedom vehicle model for different excitations. For vehicles travelling on different road profiles, comfort improvements (in terms of weighted root mean squared vertical acceleration) between $10 \%$ and $22 \%$ were obtained, with higher improvements corresponding to lower quality roads and higher passenger masses. For vehicles traversing a speed bump at different speeds, comfort improvements (in terms of peak vertical acceleration) of around $30 \%$ were obtained in all the tests considered. Future works may focus on active control of PLA pressure to achieve zero dynamic stiffness in a wider range of displacements.

Author Contributions: Conceptualization and methodology, A.L.M. and A.J.N.; validation, J.M.C.; formal analysis, investigation and data curation, E.P.; writing-original draft preparation, P.P.; supervision, J.M.C. and P.P.; funding acquisition, P.P., J.M.C., A.J.N. and A.L.M. All authors have read and agreed to the published version of the manuscript.

Funding: This research was funded by MINECO-AEI-FEDER (Spain-UE) Grant TRA-2017-83376-R, "Amortiguadores magnetoreológicos, absorsores dinámicos y paneles viscoelásticos para mejora del confort de vehículos ferroviarios con estructuras aligeradas y carga variable", and by JCCM-FEDER (Junta de Comunidades de Castilla-La Mancha, UE) Grant SBPLY/19/180501/000142 “Mejora del confort mediante el incremento de la capacidad de amortiguamiento".

Conflicts of Interest: The authors declare no conflict of interest.

\section{Abbreviations}

The following abbreviations are used in this manuscript:

$\begin{array}{ll}\text { NSS } & \text { Negative Stiffness System } \\ \text { PLA } & \text { Pneumatic Linear Actuator } \\ \text { MR } & \text { Magnetorheological } \\ \text { LVDT } & \text { Linear Variable Differential Transformer } \\ \text { PSD } & \text { Power Spectral Density }\end{array}$

\section{References}

1. Corbridge, C.; Griffin, M.J. Vibration and comfort: Vertical and lateral motion in the range 0.5 to $5.0 \mathrm{~Hz}$. Ergonomics 1986, 29, 249-272. [CrossRef]

2. Griffin, M.J. Handbook of Human Vibration; Academic Press Limited: London, UK, 1990. 
3. Mansfield, N.J.; Griffin, M.J. Comparison of biodynamic responses in standing and seated human bodies. J. Sound Vib. 2000, 238, 691-704.

4. Matsumoto, Y.; Griffin, M.J. Dynamic response of the standing human body exposed to vertical vibration: Influence of posture and vibration magnitude. J. Sound Vib. 1998, 212, 81-94. [CrossRef]

5. International Standard Organization. ISO-2631-1 Guide for the Evaluation of Human Exposure to Whole-Body Vibration, Part 1: General Requirements; International Standard Organization: Geneva, Switzerland, 2010.

6. European Standards. EN-12299 Railway Applications. Ride Comfort for Passengers. Measurement and Evaluation; European Standards: Krimicka, Czech Republic, 2009.

7. Maciejewski, I.; Meyer, L.; Krzyzynski, T. Modelling and multi-criteria optimisation of passive seat suspension vibro-isolating properties. J. Sound Vib. 2009, 324, 520-538. [CrossRef]

8. Maciejewski, I.; Kiczkowiak, T.; Krzyzynski, T. Application of the Pareto-optimal approach for selecting dynamic characteristics of seat suspension systems. Veh. Syst. Dyn. 2011, 49, 1929-1950. [CrossRef]

9. Wan, Y.; Schimmels, J.M. Optimal Seat Suspension Design Based on Minimum “Simulated Subjective Response". J. Biomech. Eng. 1997, 119, 409-416. [CrossRef]

10. Wan, Y.; Schimmels, J.M. Improved vibration isolation seat suspension designs based on position-dependent nonlinear stiffness and damping characteristics. J. Dyn. Syst. Meas. Control 2003, 125, 330-338. [CrossRef]

11. Bouazara, M; Richard, M.J.; Rakheja, S. Safety and comfort analysis of a 3-D vehicle model with optimal non-linear active seat suspension. J. Terramech. 2006, 43, 97-118. [CrossRef]

12. Abbas, W.; Emam, A.; Badran, S.; Shebl, M.; Abouelatta, O. Optimal seat suspension design for a half-car with driver model using genetic algorithm. Intell. Control Autom. 2013, 4, 199-205. [CrossRef]

13. Hostens, I.; Deprez, K; Ramon, H. An improved design of air suspension for seats of mobile agricultural machines. J. Sound Vib. 2004, 276, 141-156. [CrossRef]

14. Shimogo, T.; Oshinoya, Y.; Shinjyo, H. Active Suspension of Truck Seat. Trans. Jpn. Soc. Mech. Eng. Ser. C 1996, 62, 3132-3138. [CrossRef]

15. Stein, G.J. A Driver's Seat with Active Suspension of Electropneumatic Type. J. Vib. Acoust. 1997, 119, 230-235. [CrossRef]

16. Choi, S.B.; Choi, J.H.; Lee, Y.S.; Han, M.S. Vibration Control of an ER Seat Suspension for a Commercial Vehicle. J. Dyn. Syst. Meas. Control 2003, 125, 60-68. [CrossRef]

17. Guclu, R. Fuzzy Logic Control of Seat Vibrations of a Non-Linear Full Vehicle Model. Nonlinear Dyn. 2005, 40, 21-34. [CrossRef]

18. Du, H.; Li, W.; Zhang, N. Semi-active variable stiffness vibration control of vehicle seat suspension using an MR elastomer isolator. Smart Mater. Struct. 2011, 20, 105003-105010. [CrossRef]

19. Phu, D.X.; Choi, S.M.; Choi, S.B. A new adaptive hybrid controller for vibration control of a vehicle seat suspension featuring MR damper. J. Vib. Control 2017, 23, 3392-3413. [CrossRef]

20. Maciejewski, I.; Kiczkowiak, T.; Meyer, H. Modelling and vibration control of an active horizontal seat suspension with pneumatic muscles. J. Vib. Control 2018, 24, 5938-5950. [CrossRef]

21. Lee, C.M.; Goverdovskiy, V.N.; Temnikov, A.I. Design of springs with "negative" stiffness to improve vehicle driver isolation. J. Sound Vib. 2007, 302, 865-874. [CrossRef]

22. Lee, C.M.; Goverdovskiy, V.N. A multi-stage high-speed railroad vibration isolation system with "negative" stiffness. J. Sound Vib. 2012, 331, 914-921. [CrossRef]

23. Le, T.D.; Ahn, K.K. A vibration isolation system in low frequency excitation region using negative stiffness structure for vehicle seat. J. Sound Vib. 2011, 330, 6311-6335. [CrossRef]

24. Le, T.D.; Ahn, K.K. Experimental investigation of a vibration isolation system using negative stiffness structure. Int. J. Mech. Sci. 2013, 70, 99-112. [CrossRef]

25. Le, T.D.; Ahn, K.K. Active pneumatic isolator system using negative stiffness structure for a vehicle seat. J. Sound Vib. 2014, 333, 1245-1268.

26. Oyelade, A.O. Vibration isolation using a bar and an Euler beam as negative stiffness for vehicle seat comfort. Adv. Mech. Eng. 2019, 11,1-10. [CrossRef]

27. Tu, L.; Ning, D.; Sun, S.; Li, W.; Huang, H.; Dong, M.; Du, H. A novel negative stiffness magnetic spring design for vehicle seat suspension system. Mechatronics 2020, 68, 102370. [CrossRef]

28. Palomares, E.; Nieto, A.J.; Morales, A.L.; Chicharro, J.M.; Pintado, P. Numerical and experimental analysis of a vibration isolator equipped with a negative stiffness system. J. Sound Vib. 2018, 414, 31-42. [CrossRef] 
29. Palomares, E.; Nieto, A.J.; Morales, A.L.; Chicharro, J.M.; Pintado, P. Dynamic behaviour of pneumatic linear actuators. Mechatronics 2017, 45, 37-48. [CrossRef]

30. Gillespie, T.D. Fundamental of Vehicle Dynamics; SAE: Warrendale, PA, USA, 1992.

31. Jazar, R.N. Vehicle Dynamics—Theory and Applications; Springer: New York, NY, USA, 2014.

Publisher's Note: MDPI stays neutral with regard to jurisdictional claims in published maps and institutional affiliations.

(C) 2020 by the authors. Licensee MDPI, Basel, Switzerland. This article is an open access article distributed under the terms and conditions of the Creative Commons Attribution (CC BY) license (http://creativecommons.org/licenses/by/4.0/). 